\title{
Índices de falha de transferência de imunidade passiva (FTIP) em bezerros holandeses e nelores, às 24 e 48 horas de vida: valores de proteína total, de gamaglobulina, de imunoglobulina $\mathrm{G}$ e da atividade sérica de gamaglutamiltransferase, para o diagnóstico de FTIP ${ }^{1}$
}

\author{
Francisco L. F. Feitosa ${ }^{2 *}$, Diogo G. Camargo ${ }^{3}$, Rodrigo Yanaka ${ }^{3}$, Luiz C. N. \\ Mendes $^{2}$, Juliana R. Peiró ${ }^{2}$, Fernanda Bovino ${ }^{3}$, Júlio A. N. Lisboa ${ }^{4}$, Sílvia H. V. \\ Perri $^{2}$ e Everton R. F. Gasparelli ${ }^{3}$

\begin{abstract}
Feitosa F.L.F., Camargo D.G., Yanaka R., Mendes L.C.N, Peiró J.R., Bovino F., Lisboa J.A.N., Perri S.H.V. \& Gasparelli E.R.F. 2010. [Index of failure of passive transfer (FPT) in Holstein and Nelore calves at 24 and 48 hours of life: suggestion of total protein, gamma globulin, immunoglobulin $\mathrm{G}$ and gamma glutamyl transferase serum activity values for diagnosis of FPT.] Índices de falha de transferência de imunidade passiva (FTIP) em bezerros holandeses e nelores, às 24 e 48 horas de vida: valores de proteína total, de gamaglobulina, de imunoglobulina $\mathrm{G}$ e da atividade sérica de gamaglutamiltransferase, para o diagnóstico de FTIP. Pesquisa Veterinária Brasileira 30(8):696-704. Curso de Medicina Veterinária, Universidade Estadual Paulista, Campus de Araçatuba, Rua Clóvis Pestana 793, Araçatuba, SP 16050-680, Brazil. E-mail: leydsonf@fmva.unesp.br

In an attempt to determine the passive immunity failure in Holstein and Nelore calves, 413 blood samples were drawn from animals from both breeds. Calves born from pluriparous cows, from both breeds, and Holstein calves had greater serum concentrations of total protein, gamma globulin and IgG than Nelore newborns. However, the passive immune failure index was higher in Holstein calves than those found in Nelore calves at 24 and 48 hours. Some values of serum components were established to predict the passive immunity failure in dependency of environmental antigenic challenge.
\end{abstract}

INDEX TERMS: Calf, IgG, passive immunity.

RESUMO.- Com o objetivo de determinar os índices de falha de transferência de imunidade em bezerros holandeses e nelores foram selecionadas, aleatoriamente, 413 amostras sanguíneas de animais de ambas as raças. Os filhos de vacas pluríparas e os bezerros holandeses apresentaram maiores níveis séricos de proteína total, da fração gamaglobulina e de IgG, do que bezerros da raça Nelore. Contudo, os índices de falha de transferência de

\footnotetext{
${ }^{1}$ Recebido em 24 de outubro de 2009.

Aceito para publicação em 7 de abril de 2010.

2 Departamento de Clínica, Cirurgia e Reprodução Animal, Curso de Medicina Veterinária, Universidade Estadual Paulista (Unesp), Campus de Araçatuba, Rua Clóvis Pestana 793, Araçatuba, SP 16050-680, Brasil. *Autor para correspondência: leydsonf@fmva.unesp.br

${ }^{3}$ Pós-Graduando do Curso de Ciência Animal, área de Fisiopatologia Médica e Cirúrgica, Curso de Medicina Veterinária da Unesp, Campus de Araçatuba, SP.

${ }^{4}$ Departamento de Clínicas Veterinárias, Centro de Ciências Agrárias, Universidade Estadual de Londrina (UEL), Campus Universitário, Londrina, PR 86051-990, Brasil.
}

imunidade passiva foram mais elevados nos animais da raça Holandesa, às 24 e 48 horas de idade. Estabeleceram-se valores de alguns componentes séricos para o diagnóstico de falha de transferência de imunidade passiva, de acordo com o desafio antigênico ambiental.

TERMOS DE INDEXAÇÃO: Bezerro, IgG, imunidade passiva.

\section{INTRODUÇÃO}

A inadequada transferência de imunidade passiva torna o neonato alvo fácil para as infecções bacterianas e virais (Perino et al. 1995). A ocorrência de enfermidades depende do balanço entre a imunidade passiva adquirida e o desafio antigênico encontrado no ambiente. $O$ colostro é o mais importante exemplo de imunidade passiva (Cortese 2009). Quando os neonatos não conseguem absorver quantidades suficientes de anticorpos colostrais, chegam a condição imune denominada falha na transferência de imunidade passiva (FTIP). 
A taxa de bezerros hipogamaglobulinêmicos é geralmente alta (Norheim \& Simensen 1985). Existem pesquisas que apontam alto índice de falha na transferência de imunidade passiva, demonstrando que, em alguns rebanhos, estes valores chegam a $40 \%$ dos animais nascidos (McGuire \& Adams 1982, Barragry 1997).

A análise das taxas de imunoglobulinas séricas é considerada método objetivo na avaliação do estado funcional do sistema imunológico de bezerros neonatos (Feitosa et al. 2001). Halliwell \& Gorman (1989) sugerem que os neonatos com menos de $0,8 \mathrm{~g} / \mathrm{dL}$ de lgG 1 sérica sejam considerados animais com falha na transferência de imunidade passiva; aqueles com valores entre 0,8 e 1,6g/dL, sofreram inadequada transferência; e, bezerros com mais de $1,6 \mathrm{~g} / \mathrm{dL}$ de $\lg _{1}$, possuem adequada transferência de imunidade passiva.

Wittum \& Perino (1995), avaliando o soro sanguíneo de 263 bezerros da raça Holandesa, às 24 horas de vida, consideraram concentrações séricas de lgG superiores a 1,6g/ $\mathrm{dL}$ como adequadas; de 0,8 a $1,6 \mathrm{~g} / \mathrm{dL}$, como níveis marginais; e, menores do que $0,8 \mathrm{~g} / \mathrm{dL}$, como indicativas de hipogamaglobulinemia. Pugh (2002) acredita que níveis inferiores de $0,6 \mathrm{~g} / \mathrm{dL}$ podem significar falha de transferência de imunidade passiva, em cordeiros e cabritos.

Naylor et al. (1977) registraram doenças em 59\% dos animais com menos de $6,0 \mathrm{~g} / \mathrm{dL}$ de proteína total, após a ingestão de colostro, enquanto que, em animais com teores acima de $6,0 \mathrm{~g} / \mathrm{dL}$, a taxa foi de apenas $19 \%$. Rea et al. (1996), trabalhando com 246 bezerros holandeses, observaram que animais com menos de $4,5 \mathrm{~g} / \mathrm{dL}$ de proteína sérica, após a ingestão de colostro, apresentavam alto risco de mortalidade.

O uso da atividade sérica da GGT como medida indireta da ingestão de colostro é parâmetro confiável, uma vez que atividade menor do que $300 \mathrm{UI} / \mathrm{L}$ está correlacionada a baixos níveis séricos de gamaglobulinas (Paris et al. 1992). Por outro lado, Radostits et al. (2007) relataram que atividades de GGT menores do que $50 \mathrm{UI} / \mathrm{L}$ indicam falha de transferência de imunidade passiva.

O objetivo principal foi determinar a ocorrência de falha de transferência de imunidade passiva (FTIP) em bezerros holandeses e nelores, em propriedades localizadas na região de Araçatuba/SP, às 24 e 48 horas de vida. Tendo em vista a utilização, por pesquisadores brasileiros, de valores preconizados para rebanhos norte-americanos e a grande variabilidade nas concentrações de imunoglobulina sérica $G$ (ou de seus indicadores indiretos) na avaliação do estado imunológico de bezerros recém-nascidos, sugere-se novas conceituações para o estabelecimento do diagnóstico de FTIP.

\section{MATERIAL E MÉTODOS}

\section{Animais}

Para a avaliação dos índices de falha de transferência de imunidade passiva foram utilizados 413 bezerros, produtos de partos eutócicos, sendo 205 da raça Holandesa e 208 da raça Nelore, de acordo com o número de animais presentes nas propriedades no momento da colheita. Obti- veram-se, aleatoriamente, 100 amostras sanguíneas de animais da raça Holandesa e 105 de bezerros nelores, às 24 horas pós-nascimento; e, às 48 horas de vida, 105 e 103 amostras, respectivamente. Colheu-se uma única amostra sanguínea de cada animal, evitando-se a duplicidade de resultados, pois animais que apresentassem baixos níveis circulantes de imunoglobulina $\mathrm{G}$ (ou de seus indicadores) ao final do primeiro dia de vida, também os apresentariam às 48 horas de idade. Os bezerros foram agrupados levando-se em consideração a raça, o horário das colheitas sanguíneas e o número de parições das mães (primípara ou plurípara). A maioria dos animais pertencentes à raça Holandesa era proveniente de propriedades produtoras de leite tipo $A, B$ e $C$, localizadas na região de Araçatuba/SP, mantidos sob condições padrões de criação. Nestes animais realizou-se o curativo do umbigo duas vezes ao dia, com solução de iodo a $2 \%$, durante os três primeiros dias. Os animais da raça Nelore eram oriundos de três propriedades localizadas na região de Araçatuba/ $\mathrm{SP}$, que praticavam manejo extensivo convencional sob condições naturais, com controle individual do plantel e bom padrão de manejos nutricional e sanitário. Realizouse a higiene do umbigo com produto à base de iodofórmio, fenol, ácido pícrico e diclórvós ${ }^{4}$, uma única vez, no primeiro dia de vida.

Todos os bezerros holandeses permaneciam em contato com as suas mães, desde o nascimento até as 24 horas de vida, sendo alimentados, a partir de então, com leite comercial. Os bezerros nelores permaneceram constantemente com as mães, até o período do desmame (quatro meses).

\section{Processamento do material}

As colheitas de sangue para a obtenção de soro foram realizadas após antissepsia local, por venopunção jugular, utilizando-se agulhas $25 \times 0,7 \mathrm{~mm}^{5}$, acopladas a tubos à vácuo siliconizados sem anticoagulante ${ }^{6}$. 0 sangue, em volume total de $20 \mathrm{~mL}$, era mantido à temperatura ambiente até a coagulação e retração visível do coágulo, sendo, posteriormente, centrifugado a 3.000 r.p.m., durante 10 minutos, para melhor separação do soro. Este era transferido para frascos de plástico apropriados ${ }^{7}$ com auxílio de pipeta automática e congelado imediatamente em "freezer"8 a $-20^{\circ} \mathrm{C}$, até o momento do seu processamento.

Determinou-se a proteína total sérica pelo método do Biureto, segundo Gornall et al. (1949), modificado por Strufaldi (1987), usando-se para tal o analisador bioquímico RA $-100^{9}$ em comprimento de onda de $555 \mathrm{~nm}$.

A migração eletroforética para separação das frações protéicas do soro sanguíneo dos animais que constituíram

\footnotetext{
4 Umbicura $^{\circledR}$.

${ }^{5}$ PrecisionGlide, $\mathrm{BD}^{\circledR}$.

${ }^{6}$ Vacutainer $^{\circledR}$.

7 Eppendorff ${ }^{\circledR}$.

8 Prosdócimo ${ }^{\circledR}$.

${ }^{9}$ Bayer, Techinicom, modelo RA $100^{\text {tm }}$ system.
} 
os grupos experimentais foi efetuada segundo as técnicas descritas por Friedman (1961) e Kremers et al. (1967).

A leitura e a interpretação do fracionamento eletroforético foram realizadas em densitometro para eletroforese ${ }^{10}$, pelo programa Multi analystt (Bio-rad Laboratories ${ }^{\circledR}$, Hercules, CA), com marcação automática das diferentes frações protéicas (albumina, alfaglobulina, betaglobulina e gamaglobulina).

As determinações da imunoglobulina $G$ eram feitas segundo a técnica de Fahey \& McKelvey (1965) e Mancini et al. (1965), utilizando-se placas de ágar incorporadas com antisoros específicos para a classe de imunoglobulina $\mathrm{G}^{11}$ de bovinos. Com o auxílio de pipeta especial ${ }^{12}$, colocouse $5 \mu l$ do soro sanguíneo em análise, nas placas específicas para determinação quantitativa de lgG, sendo mantidas em repouso à temperatura ambiente $\left( \pm 22^{\circ} \mathrm{C}\right)$, por um período mínimo de 72 horas. Após esse tempo, observava-se a formação do halo de precipitação ao redor das cavidades onde foram colocadas as amostras, decorrente da reação antígeno-anticorpo.

Fazia-se a medição do diâmetro do referido anel e a quantidade de imunoglobulina em questão era então estimada, observando-se a concentração de imunoglobulinas correspondente a cada amostra, através da construção, no computador, de um gráfico com os valores obtidos para os respectivos padrões de IgG, fornecidos pela firma fornecedora dos kits.

Todas as análises bioquímicas foram realizadas em analisador bioquímico automatizado ${ }^{13}$, previamente calibrado

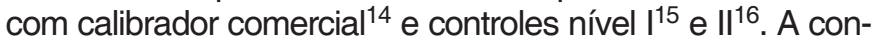
centração sérica da gamaglutamiltransferase (GGT) foi determinada de acordo com o método cinético colorimétrico recomendado pela International Federation of Clinical Chemistry (IFCC), usando-se kit comercial para gamaglutamiltransfera$\mathrm{se}^{17}$, segundo técnica modificada de Szasz (1969).

\section{Análise estatística}

Os dados foram testados quanto à normalidade (Teste Kolmogorov-Smirnov) e homocedasticidade (Teste Bartlett).

Para a variável proteína total utilizou-se o teste t não pareado para verificação da existência de diferença entre os grupos por número de parições (vacas primíparas ou pluríparas) e raças (Holandesa e Nelore). Para as variáveis gamaglobulina, imunoglobulina $\mathrm{G}$ e gamaglutamiltransferase (GGT) utilizou-se o teste de Mann-Whitney para comparação entre os grupos. Foram calculados os coeficientes de correlação de Pearson e de Spearman, entre as variáveis proteína total e suas frações, bem como para a

\footnotetext{
10 Helena.

${ }^{11}$ VMRD, Inc. (Nos séries: P060928-001 / P060426-001).

12 USA Scientific (0,5-10ul), USA Scientific Plastics.

${ }^{13}$ Analisador automático BTS, mod. 370 plus, BioSystems, Spain.

14 Calibrator serum, Cód.18011, BioSystems, Spain.

15 Assayed control serum level I, Cód. 18005, BioSystems, Spain.

${ }^{16}$ Assayed control serum level II, Cód. 18007, BioSystems, Spain.

17 Gamma-glutamyltransferase ( $\gamma$-GT), Cod.11584, BioSystems, Spain.
}

imunoglobulina G. As análises estatísticas foram efetuadas empregando-se o programa computacional SAS (Statistical Analysis System ${ }^{\circledR}$ ), segundo Zar (1999). As análises foram consideradas significativas quando $p<0,05$.

\section{RESULTADOS E DISCUSSÃO}

A avaliação da transferência de imunidade passiva colostral deve ser feita, preferencialmente, entre 24 e 48 horas de vida, que é o período de concentração máxima das imunoglobulinas maternas no soro sanguíneo de bezerros (Barrington \& Parish 2002). A determinação da ocorrência ou não, de falha de transferência de imunidade passiva neste período é importante do ponto de vista clínico, já que viabilizaria imediata intervenção veterinária, visando a minimizar os possíveis riscos de infecções. A utilização do termo "falha de transferência de imunidade passiva (FTIP)" para definir níveis insatisfatórios de proteção imune no animal recém-nascido exige, obrigatoriamente, a definição de parâmetros de normalidade para os teores de alguns componentes séricos circulantes.

A avaliação dos animais, quanto ao sucesso ou não na obtenção da imunidade passiva, tem como base a determinação direta ou indireta da concentração das imunoglobulinas circulantes no soro dos recém-nascidos. Realizou-se a avaliação direta pela mensuração das diferentes classes de imunoglobulinas, quais sejam, IgG e lgM, e indireta, pelas variáveis que possuíam correlação com os teores de imunoglobulinas, tais como as concentrações séricas de proteína total e da fração gamaglobulina, como observado no Quadro 1, às 24 e 48 horas. Observou-se correlação significativa entre estas variáveis e a lgG, permitindo inferir que

\begin{tabular}{|c|c|c|}
\hline \multicolumn{3}{|c|}{$\begin{array}{l}\text { Quadro 1. Coeficientes de correlação } \\
\text { entre as variáveis séricas: proteína } \\
\text { total (PT), das frações albumina (ALB), } \\
\text { alfaglobulina (ALFA), betaglobulina } \\
\text { (BETA), gamaglobulina (GAMA) e da } \\
\text { imunoglobulina G (IgG) de bezerros, } \\
\text { às } 24 \text { e } 48 \text { horas pós-nascimento }\end{array}$} \\
\hline \multirow[t]{2}{*}{ Variáveis } & \multicolumn{2}{|c|}{ Momento } \\
\hline & $24 \mathrm{~h}$ & $48 \mathrm{~h}$ \\
\hline $\mathrm{PTXALB}^{(1)}$ & 0,215 & $0,455^{\star}$ \\
\hline $\operatorname{PTxALFA}^{(1)}$ & 0,145 & 0,108 \\
\hline $\mathrm{PT} \mathrm{BETA}^{(1)}$ & $0,547^{*}$ & $0,736^{\star}$ \\
\hline $\mathrm{PTxGAMA}^{(2)}$ & $0,556^{*}$ & $0,896^{*}$ \\
\hline PTxlgG(2) & $0,861^{*}$ & $0,860^{*}$ \\
\hline $\operatorname{ALBXALFA}^{(1)}$ & $-0,014$ & $-0,144$ \\
\hline $\operatorname{ALBxBETA}^{(1)}$ & $-0,073$ & $0,317^{*}$ \\
\hline ALBxGAMA $^{(2)}$ & 0,018 & 0,134 \\
\hline $\operatorname{ALBxIgG}^{(2)}$ & 0,031 & 0,185 \\
\hline ALFAxBETA $^{(1)}$ & $-0,152$ & $-0,066$ \\
\hline $\operatorname{ALFAxGAMA}^{(2)}$ & 0,133 & 0,037 \\
\hline ALFAxlgG(2) & 0,286 & 0,036 \\
\hline BETAxGAMA $^{(2)}$ & $0,643^{*}$ & $0,599^{*}$ \\
\hline BETAxlgG $^{(2)}$ & $0,511^{*}$ & $0,585^{*}$ \\
\hline GAMAxIgG(2) $^{(2)}$ & $0,902^{*}$ & $0,902^{*}$ \\
\hline
\end{tabular}

\footnotetext{
(1) Coeficiente de correlação de Pearson.

(2) Coeficiente de correlação de Spearman.

* Correlação significativa $(p<0,05)$.
} 
Quadro 2. Valores indicativos de falha de transferência de imunidade passiva em bezerros segundo os diferentes autores

\begin{tabular}{lcccc}
\hline \multicolumn{1}{c}{ Autor } & PT & Gamaglobulina & IgG & GGT \\
\hline Naylor et al. (1977) & $<6,0 \mathrm{~g} / \mathrm{dL}$ & - & - & - \\
Halliwell \& Gorman (1989) & - & - & $800 \mathrm{mg} / \mathrm{dL}$ & - \\
Paris et al. (1992) & - & - & - & $<300 \mathrm{UI} / \mathrm{L}$ \\
Heath (1992) & $<5,5 \mathrm{~g} / \mathrm{dL}$ & - & - & - \\
Perino et al. (1993) & $4,2 \mathrm{~g} / \mathrm{dL}$ & - & $<800 \mathrm{mg} / \mathrm{dL}$ & $<200 \mathrm{UI} / \mathrm{L}$ \\
Biswal et al. (1993) & $4,8 \mathrm{~g} / \mathrm{dL}$ & $<1,5 \mathrm{~g} / \mathrm{dL}$ & - & - \\
Wittum \& Perino (1995) & $<4,8 \mathrm{~g} / \mathrm{dL}$ & - & $<800 \mathrm{mg} / \mathrm{dL}$ & - \\
Selim et al. (1995) & - & - & $<500 \mathrm{mg} / \mathrm{dL}$ & - \\
Rea et al. (1996) & $4,5 \mathrm{~g} / \mathrm{dL}$ & - & - & - \\
Feitosa et al. (2001) & & $<1,0 \mathrm{~g} / \mathrm{dL}$ & - & - \\
Smith (2002) & $5,0 \mathrm{~g} / \mathrm{dL}$ & - & - & - \\
Radostits et al. (2007) & - & $0,5 \mathrm{~g} / \mathrm{dL}$ & $<1000 \mathrm{mg} / \mathrm{dL}$ & $50 \mathrm{UI} / \mathrm{L}$
\end{tabular}

ambas podem ser utilizadas como parâmetros para avaliação da transferência de imunidade passiva, como foi demonstrado em outros estudos realizados com bezerros (Perino et al. 1993, Fagliari et al. 1996, Feitosa et al. 2001).

A distribuição das porcentagens dos intervalos dos valores para alguns componentes séricos, observada neste experimento, encontra-se demonstrada nos Quadros 3 a 6. Esses resultados divergiram daqueles compulsados na literatura, como Naylor et al. (1977), Heath (1992), Wittum \& Perino (1995), Rea et al. (1996) e Smith (2002), quanto à definição de valor sérico ideal de proteína total em bezerros recém-nascidos que lhes conferisse adequada proteção imune. Pela classificação de Naylor et al. (1977), óbitos em bezerros foram observados em animais que apresentavam concentração sérica de proteína total menor ou igual a $6 \mathrm{~g} / \mathrm{dL}$ (Quadro 2). No mesmo período de vida (24 e 48 horas), os resultados individuais, ora obtidos, demonstraram que, para a concentração de proteína total no soro sanguíneo, 36\% (36/100) e 30,4\% (32/105) dos bezerros da raça Holandesa eram possuidores de faIha de imunidade passiva, enquanto nos da raça Nelore esses índices foram de 44,27\% (58/131) e 49,5\% (51/103). Dos animais utilizados neste trabalho, cerca de 22,0\% (22/ $100)$ e $28 \%$ (30/105) dos bezerros da raça Holandesa, e de $44,3 \%$ (58/131) e 45,6\% (47/103) daqueles da raça Nelore apresentariam o mesmo problema, às 24 e 48 horas, caso fosse considerado o conceito de estratificação apresentado por Heath (1992), que postulou valor sérico mínimo de $5,5 \mathrm{~g} / \mathrm{dL}$ de proteína total, para que houvesse proteção

Quadro 3. Variação da concentração sérica da proteína total (PT), segundo o número e porcentagem de bezerros, de acordo com a raça e a idade dos animais

\begin{tabular}{cccccc}
\hline \multirow{2}{*}{ Variação } & \multicolumn{2}{c}{ Holandês } & & \multicolumn{2}{c}{ Nelore } \\
\cline { 2 - 3 } \cline { 5 - 6 } & $24 \mathrm{~h}$ & $48 \mathrm{~h}$ & & $24 \mathrm{~h}$ & $48 \mathrm{~h}$ \\
\hline \multirow{2}{*}{ Até $4,0 \mathrm{~g} / \mathrm{dL}$} & $3 / 100$ & $0 / 105$ & & $3 / 131$ & $0 / 103$ \\
& $(3 \%)$ & $(0 \%)$ & & $(2,3 \%)$ & $(0 \%)$ \\
$4,1-5,0 \mathrm{~g} / \mathrm{dL}$ & $7 / 100$ & $9 / 105$ & & $19 / 131$ & $20 / 103$ \\
& $(7 \%)$ & $(9,1 \%)$ & & $(14,5 \%)$ & $(19,4 \%)$ \\
$5,1-6,0 \mathrm{~g} / \mathrm{dL}$ & $26 / 100$ & $23 / 105$ & & $36 / 131$ & $27 / 103$ \\
& $(26 \%)$ & $(21,3 \%)$ & & $(27,5 \%)$ & $(26,2 \%)$ \\
$>6,0 \mathrm{~g} / \mathrm{dL}$ & $64 / 100$ & $73 / 105$ & $73 / 131$ & $56 / 103$ \\
& $(64 \%)$ & $(69,6 \%)$ & $(55,7 \%)$ & $(54,4 \%)$
\end{tabular}

satisfatória dos animais recém-nascidos contra agentes agressores. Se fossem seguidos os critérios sugeridos por Smith (2002), Biswal et al. (1993), Wittum \& Perino (1995) e Rea et al. (1996), para os quais haveria falha de transferência de imunidade passiva nos bezerros com valores mínimos de proteína total de 5,0, 4,8 e 4,5g/dL, estas porcentagens seriam, respectivamente, de 10\% (10/100), $12,3 \%(13 / 105)$ e de $10 \%(10 / 100)$ para os animais da raça Holandesa, e de 16\% (22/131), 15,3\% (20/131) e 7,6\% (10/ 131) para os bezerros nelores, às 24 horas; seriam de $9,5 \%(10 / 105), 9 \%(9 / 100)$ e $7 \%(6,7 \%)$, e de $17,4 \%(18 /$ $103), 15,5 \%$ (16/103) e 5,8\% (6/103) para os bezerros holandeses e nelores, respectivamente, às 48 horas de vida.

Donovan et al. (1986) constataram maior mortalidade por doenças infecciosas, durante as primeiras semanas de vida, nos bezerros com menores concentrações séricas das frações beta e gamaglobulinas. No presente estudo, pela falta de acompanhamento dos animais em virtude do seu elevado número, não foi possível obtenção de tal correlação. Entretanto, torna-se difícil o estabelecimento das taxas de falhas de transferência de imunidade passiva, levando-se em consideração apenas as respectivas frações, pela escassez de informações na literatura nacional e internacional com tal finalidade. Cabe ressaltar os trabaIhos de Feitosa et al. (2001) que constataram 17,5\% (7/40) de bezerros possuidores de concentração sérica média da fração gamaglobulina menor do que $1,00 \mathrm{~g} / \mathrm{dL}$, sendo que seis daqueles animais morreram nos primeiros quinze dias de vida, e o trabalho de Biswal et al. (1993) que considerou

Quadro 4. Variação da concentração sérica da fração gamaglobulina, segundo o número e porcentagem de bezerros, de acordo com a raça e a idade dos animais

\begin{tabular}{cccccc}
\hline \multirow{2}{*}{ Variação } & \multicolumn{3}{c}{ Holandês } & & \multicolumn{2}{c}{ Nelore } \\
\cline { 2 - 3 } \cline { 5 - 6 } & $24 \mathrm{~h}$ & $48 \mathrm{~h}$ & & $24 \mathrm{~h}$ & $48 \mathrm{~h}$ \\
\hline Até $0,50 \mathrm{~g} / \mathrm{dL}$ & $8 / 100$ & $7 / 105$ & & $2 / 131$ & $0 / 103$ \\
& $(8 \%)$ & $(6,7 \%)$ & & $(1,5 \%)$ & $(0 \%)$ \\
$0,51-1,0 \mathrm{~g} / \mathrm{dL}$ & $10 / 100$ & $9 / 105$ & & $23 / 131$ & $21 / 103$ \\
& $(10 \%)$ & $(8,6 \%)$ & & $(17,6 \%)$ & $(20,4 \%)$ \\
$1,1-1,5 \mathrm{~g} / \mathrm{dL}$ & $15 / 100$ & $18 / 105$ & & $29 / 131$ & $29 / 103$ \\
& $(15 \%)$ & $(17,1 \%)$ & & $(22,1 \%)$ & $(28,1 \%)$ \\
$>1,5 \mathrm{~g} / \mathrm{dL}$ & $67 / 100$ & $71 / 105$ & & $77 / 131$ & $53 / 103$ \\
& $(67 \%)$ & $(67,6 \%)$ & & $(58,8 \%)$ & $(51,5 \%)$
\end{tabular}


valores menores do que $1,5 \mathrm{~g} / \mathrm{dL}$ como concentrações inadequadas. No presente estudo, 18\% (18/100) e 15,3\% (16/ $105)$ dos bezerros holandeses, e $18,3 \%$ (24/131) e $20,3 \%$ (20/103) dos animas da raça Nelore, às 24 e 48 horas de vida, respectivamente, apresentaram concentrações médias de até $1,0 \mathrm{~g} / \mathrm{dL}$ da referida fração. Contudo, a grande maioria dos animais (67\%) possuíam teores médios superiores a $1,5 \mathrm{~g} / \mathrm{dL}$ nos momentos supramencionados. Constatou-se, entretanto, menor porcentagem para os animais da raça Nelore, já que apenas 44\% (157/234) tinham teores acima dos descritos, o que determinaria, tendo em vista os conceitos supracitados, taxa de $56 \%$ de FTIP.

As dosagens de imunoglobulinas séricas representam método confiável para determinar a eficiência da ingestão de colostro, nos animais recém-nascidos. A absorção de IgA e IgM também é importante na prevenção de infecções; porém, como a lgG $\mathrm{G}_{1}$ é a imunoglobulina presente em maior quantidade no colostro, e como pequenas quantidades absorvidas desta imunoglobulina são correlacionadas com pequenas quantidades absorvidas das outras, utilizam-se os níveis de lgG para estabelecer estimativas de proteção para o neonato (Feitosa et al. 2001). Ao associar as afirmações de Halliwell \& Gorman (1989) e Wittum \& Perino (1995), que consideraram as concentrações séricas de IgG maiores do que $1600 \mathrm{mg} / \mathrm{dL}$ como adequadas, as concentrações variando de 800 a $1600 \mathrm{mg} / \mathrm{dL}$ como níveis marginais e, as menores do que $800 \mathrm{mg} / \mathrm{dL}$, como indicativas de hipogamaglobulinemia, constatou-se que 7,5\% (8/ $160)$ dos animais holandeses e $11,1 \%$ (26/234) dos recémnascidos da raça Nelore, com idades variando entre $24 \mathrm{e}$ 48 horas, seriam imunodeficientes.

Em bovinos adultos, a gamaglutamiltranferase (GGT) é de importância na identificação de animais com doenças hepáticas crônicas (Pearson \& Craig 1980), sendo que, em neonatos ruminantes, a atividade desta enzima no soro sanguíneo pode ser utilizada como método de avaliação da transferência de imunidade passiva (Braun et al. 1978). Ao analisar os dados individuais da atividade enzimática de GGT sérica, a maior parte dos animais da raça Holandesa possuía valores maiores do que $100 \mathrm{UI} / \mathrm{L}$, às 24 (82\%) e 48 horas $(78,7 \%)$ de vida. Da mesma forma, cerca de $80 \%$ e $95 \%$ dos bezerros nelores apresentariam o mesmo comportamento com relação à atividade sérica da respectiva enzima, às 24 e 48 horas de vida, respectivamente. Contudo, cerca de $4 \%(4 / 100)$ e 10,7\% (8/75) dos animais holandeses, e 1,5\% (2/131) e 3,8\% (4/103) dos recémnascidos da raça Nelore poderiam ser considerados como portadores de FTIP, às 24 e 48 horas de nascidos, respectivamente, caso a classificação de Radostits et al. (2007) fosse tomada como referência, pois apresentavam atividade sérica de GGT inferior a $50 \mathrm{UI} / \mathrm{L}$.

Dos 100 bezerros holandeses avaliados às 24 horas, 56 eram filhos de vacas com mais de uma parição, enquanto os animais restantes nasceram de mães primíparas. Cerca de 59\% (78/131) dos bezerros nelores com a mesma faixa etária eram oriundos de vacas pluríparas. Índices semelhantes foram observados para os animais com 48
Quadro 5. Variação da concentração sérica de imunoglobulina $\mathrm{G}$, segundo o número e porcentagem de bezerros, de acordo com a raça e a idade dos animais

\begin{tabular}{cccccc}
\hline \multirow{2}{*}{ Variação } & \multicolumn{2}{c}{ Holandês } & & \multicolumn{2}{c}{ Nelore } \\
\cline { 2 - 3 } \cline { 5 - 6 } & $24 \mathrm{~h}$ & $48 \mathrm{~h}$ & & $24 \mathrm{~h}$ & $48 \mathrm{~h}$ \\
\hline \multirow{2}{*}{ Até $400 \mathrm{~g} / \mathrm{dL}$} & $2 / 80$ & $0 / 80$ & & $0 / 131$ & $0 / 103$ \\
& $(2,5 \%)$ & $(0 \%)$ & & $(0 \%)$ & $(0 \%)$ \\
$401-800 \mathrm{mg} / \mathrm{dL}$ & $6 / 80$ & $8 / 80$ & & $2 / 131$ & $0 / 103$ \\
& $(7,5 \%)$ & $(10,0 \%)$ & & $(1,5 \%)$ & $(0 \%)$ \\
$801-1500 \mathrm{mg} / \mathrm{dL}$ & $0 / 80$ & $6 / 80$ & & $7 / 131$ & $10 / 103$ \\
& $(0 \%)$ & $(7,5 \%)$ & & $(5,3 \%)$ & $(9,7 \%)$ \\
$>1500 \mathrm{mg} / \mathrm{dL}$ & $72 / 80$ & $66 / 80$ & & $122 / 131$ & $93 / 103$ \\
& $(90 \%)$ & $(82,5 \%)$ & & $(93,2 \%)$ & $(91,3 \%)$
\end{tabular}

Quadro 6. Variação da taxa da atividade de gamaglutamiltransferase sérica, segundo o número e porcentagem de bezerros, de acordo com a raça e a idade dos animais

\begin{tabular}{cccccc}
\hline \multirow{2}{*}{ Variação } & \multicolumn{2}{c}{ Holandês } & & \multicolumn{2}{c}{ Nelore } \\
\cline { 2 - 3 } \cline { 5 - 6 } & $24 \mathrm{~h}$ & $48 \mathrm{~h}$ & & $24 \mathrm{~h}$ & $48 \mathrm{~h}$ \\
\hline \multirow{2}{*}{ Até $50 \mathrm{UI} / \mathrm{L}$} & $4 / 100$ & $8 / 75$ & & $2 / 131$ & $4 / 103$ \\
& $(4 \%)$ & $(10,7 \%)$ & & $(1,5 \%)$ & $(3,9 \%)$ \\
$51-100 \mathrm{UI} / \mathrm{L}$ & $14 / 100$ & $8 / 75$ & & $7 / 131$ & $2 / 103$ \\
& $(14 \%)$ & $(10,6 \%)$ & & $(5,3 \%)$ & $(1,9 \%)$ \\
$101-300 \mathrm{UI} / \mathrm{L}$ & $27 / 100$ & $21 / 75$ & & $13 / 131$ & $11 / 103$ \\
& $(27 \%)$ & $(28 \%)$ & & $(9,9 \%)$ & $(10,7 \%)$ \\
$>$ de 300 UI/L & $55 / 100$ & $38 / 75$ & & $109 / 131$ & $86 / 103$ \\
& $(55 \%)$ & $(50,7 \%)$ & & $(83,3 \%)$ & $(83,5 \%)$
\end{tabular}

horas de vida, de ambas as raças. Avaliando-se a influência do número de parições nos constituintes séricos de bezerros com um dia de vida, contatou-se que os animais filhos de vacas holandesas pluríparas possuíam maiores concentrações séricas de proteína total e de imunoglobulina $G$ (Quadro 7) do que o daqueles de vacas de uma única parição, fato já observado por Feitosa et al. (1999). As concentrações séricas da fração protéica gamaglobulina foram menores nos filhos de vacas da raça Nelore, mas não apresentaram influência estatisticamente significativa em relação ao número de parições das suas mães, como também constatado para a atividade de gamaglutamiltransferase, às 24 horas, para vacas primíparas de ambas as raças. Contudo, a atividade sérica de GGT demonstrou variação significativa entre ambas as raças para as vacas pluríparas, sendo maior nos bezerros criados para produção de carne.

Nos animais da raça Nelore observou-se elevado índice $(45,67 \%)$ de morbidade nos primeiros dias de vida (95/ 208). As enfermidades e/ou alterações observadas no presente trabalho foram, a saber: onfaloflebites (22/208), míases umbilicais (10/208), diarréias (8/208), hérnias umbilicais (6/208), associação das alterações acima descritas (34/208), e outras enfermidades (15/208). Tais observações não foram possíveis de serem realizadas a contento nos animais da raça Holandesa, pela falta ou falhas nas informações descritas nos registros das propriedades, acerca das causas de morbidade e a faixa etária em que as mesmas ocorreram. Contudo, pelo levantamento clínico retrospectivo de 99 bezerros, foi possível evidenciar a ocorrência de 37 casos de enterites, cinco casos de bron- 
Quadro 7. Média, desvio padrão (DP) e mediana (Md) das variáveis observados no soro sanguíneo de bezerros nelores e holandeses, às 24 horas de vida, segundo o número de parições das vacas (primípara ou plurípara)

\begin{tabular}{|c|c|c|c|c|c|c|}
\hline \multirow[t]{2}{*}{ Variável } & \multirow[t]{2}{*}{ Raça } & \multirow[t]{2}{*}{$\mathrm{n}$} & \multicolumn{2}{|c|}{ Primípara } & \multicolumn{2}{|l|}{ Plurípara } \\
\hline & & & Média \pm DP & $\mathrm{Md}$ & Média \pm DP & Md \\
\hline \multirow[t]{2}{*}{ PT (g/dL) } & Nelore & 105 & $6,06 \pm 1,18^{\mathrm{aA}}$ & - & $6,45 \pm 1,25^{\mathrm{bA}}$ & - \\
\hline & Holandesa & 100 & $5,88 \pm 1,15^{a B}$ & - & $7,08 \pm 0,90^{\mathrm{aA}}$ & - \\
\hline \multirow[t]{2}{*}{$\lg G(\mathrm{mg} / \mathrm{dL})$} & Nelore & 105 & $2696,62 \pm 845,73$ & $2756^{a A}$ & $2865,07 \pm 1196,83$ & $2774^{\mathrm{bA}}$ \\
\hline & Holandesa & 100 & $2417,64 \pm 910,24$ & $2648^{a B}$ & $4020,83 \pm 825,72$ & $4105^{\mathrm{aA}}$ \\
\hline \multirow[t]{2}{*}{ GGT (UI/L) } & Nelore & 105 & $1910,84 \pm 2335,87$ & $970^{\mathrm{aB}}$ & $2398,26 \pm 2077,05$ & $2196^{a A}$ \\
\hline & Holandesa & 100 & $774,19 \pm 548,61$ & $750^{\mathrm{aA}}$ & $672,97 \pm 448,58$ & $650^{\mathrm{bA}}$ \\
\hline \multirow[t]{2}{*}{ Gama $(\mathrm{g} / \mathrm{dL})$} & Nelore & 105 & $1,57 \pm 0,74^{\mathrm{bA}}$ & - & $1,71 \pm 0,82^{\mathrm{bA}}$ & - \\
\hline & Holandesa & 100 & $2,01 \pm 0,85^{\mathrm{aA}}$ & - & $2,18 \pm 1,07^{\mathrm{aA}}$ & - \\
\hline
\end{tabular}

Médias ou medianas seguidas de letras distintas minúsculas, na coluna, e maiúsculas, na linha, diferem entre si $(P<0,05)$.

copneumonia, três casos de onfalites, três casos de anaplasmose, três casos de broncopneumonia, associados, estes últimos, à diarréia, e um caso de babesiose. Este estudo evidenciou que as principais causas de perdas de bezerros ocorrem durante o período do periparto, pela ocorrência de doenças infecciosas.

A Imunologia de animais neonatos pecuários é área que vem despertando grande interesse. A avaliação da imunidade passiva não pode ser feita única e simplesmente pelo exame físico do animal, devendo ser utilizados, sempre que possível, exames laboratoriais. Novos e avançados métodos são cada vez mais utilizados para avaliar o estado imunológico de animais recém-nascidos (Cortese 2009). No entanto, grande é a variabilidade dos valores de alguns componentes sanguíneos adotados por diferentes autores (Quadro 2), para estabelecer a ocorrência ou não de falha de transferência de imunidade passiva. Alguns autores, por exemplo, se utilizam valores muito baixos como sendo suficientes para a proteção imune, como o relatado por Radostits et al. (2007) para a atividade enzimática de GGT, enquanto outros descreveram teores relativamente elevados para a referida enzima (Perino et al. 1993).

Deve-se ressaltar, contudo, que a utilização de um valor pontual para qualquer componente sanguíneo, visando estabelecer se um bezerro recém-nascido é ou não imunodeficiente, deve ser objeto de cautela. É temeroso afirmar que um determinado recém-nascido seja mais ou menos suscetível às diferentes enfermidades infecciosas, levando-se em consideração apenas as concentrações (ou indicadores indiretos) de imunoglobulinas séricas. Tal classificação não deve ser encarada como sendo apenas uma questão mate- mática, de jogo de números, de valores mínimos e máximos, de cálculos. Em Biologia, muitas vezes, o limite dos valores de normalidade é um tanto tênue. Além disso, é importante salientar que os níveis séricos necessários para conferir proteção a bezerros recém-nascidos são influenciados por vários fatores ambientais e pela carga de patógenos aos quais os animais são expostos (Garry et al. 1993, Guy et al. 1994). Deve-se considerar, ainda, que a imunidade humoral não é a única responsável pela defesa do organismo (Tizard 2002).

A inexistência de valores de referência para o diagnóstico de FTIP em bezerros, em nosso país, torna necessária a elaboração de novos parâmetros de variação de alguns componentes séricos, para contribuir na caracterização se um recém-nascido é imunodeficiente, entre o $1^{\circ} \mathrm{e}$ $2^{\circ}$ dias de vida. O confronto dos valores obtidos no presente trabalho com aqueles de outras pesquisas (Feitosa 1998, Feitosa \& Birgel 2000, Feitosa et al. 2001), somado à experiência adquirida ao longo do tempo na clínica de animais neonatos, levaram à proposição de critérios de classificação, visando o diagnóstico de falha de transferência de imunidade passiva (Quadro 8). A nosso ver, concentrações mínimas de imunoglobulina $G$ podem ser suficientes para minimizar riscos de doenças infecciosas, em ambientes pouco contaminados ou relativamente higiênicos, enquanto concentrações séricas mais elevadas talvez sejam requeridas por animais criados em situações higiênicas radicalmente opostas (Soares Filho et al. 2001).

Segundo a classificação adotada neste estudo, por exemplo, baixas concentrações de imunoglobulinas (400-

Quadro 8. Classificação de valores séricos de proteína total (PT), gamaglobulina, imunoglobulina G (IgG) e da atividade enzimática de gamaglutamiltransferase (GGT) para transferência de imunidade passiva em bezerros, às 24 e 48 horas de vida de acordo com a contaminação do ambiente (alta ou baixa)

\begin{tabular}{|c|c|c|c|c|}
\hline Classificação & PT & Gamaglobulina & $\lg G$ & GGT \\
\hline Auser & $<4,0 \mathrm{~g} / \mathrm{dL}$ & Até $0,50 \mathrm{~g} / \mathrm{dL}$ & Até $400 \mathrm{mg} / \mathrm{dL}$ & Até 50 UI/L \\
\hline Baixa a razoável & $4,0-5,0 \mathrm{~g} / \mathrm{dL}$ & $0,50-1,0 \mathrm{~g} / \mathrm{dL}$ & $401-800 \mathrm{mg} / \mathrm{dL}$ & 50-100 UI/L \\
\hline Razoável a boa & $5,0-6,0 \mathrm{~g} / \mathrm{dL}$ & $1,0-1,5 \mathrm{~g} / \mathrm{dL}$ & $800-1500 \mathrm{mg} / \mathrm{dL}$ & $100-300 \mathrm{UI} / \mathrm{L}$ \\
\hline Boa a excelente & $>6,0 \mathrm{~g} / \mathrm{dL}$ & $>1,5 \mathrm{~g} / \mathrm{dL}$ & $>1500 \mathrm{mg} / \mathrm{dL}$ & $>300 \mathrm{UI} / \mathrm{L}$ \\
\hline
\end{tabular}


$800 \mathrm{mg} / \mathrm{dL}$ ) podem ser insuficientes para proteger contra Escherichia coli de determinado meio, mas não contra outro tipo de cepa presente em ambiente diferente. Por outro lado, concentrações de imunoglobulinas consideradas como excelentes $(>1500 \mathrm{mg} / \mathrm{dL})$ podem não ser eficazes para prevenir o neonato contra determinados patógenos. É sabido que o gado leiteiro, geralmente confinado, vive em ambiente completamente oposto ao das condições extensivas em que são criados os bovinos de corte, exigindo a adoção de manejos diferenciados. O desafio imposto em condições de manejo extensivo é, de forma geral, menor (Costa et al. 2007). Desta forma, os animais criados para a produção de corte necessitariam, teoricamente, de menores concentrações séricas de imunoglobulinas para se protegerem das agressões antigênicas do que os bezerros criados com finalidade de produção de leite. Isto pode ser representado pelas menores concentrações séricas de lgG em bezerros da raça Nelore, às 24 horas vida, observadas no presente trabalho.

Assim, são sugeridas variações dos valores séricos, os quais devem ser interpretados levando-se em consideração, além dos níveis séricos de imunoglobulinas circulantes (e/ou de seus indicadores), outros aspectos, como: 1) Intensidade do desafio antigênico ao qual os animais recém-nascidos serão submetidos, ou seja, o nível de agressividade dos patógenos ambientais, e 2) Existência de imunoglobulinas específicas em quantidade satisfatória na circulação sanguínea e em mucosas contra os microorganismos de determinado ambiente. Apesar de estes fatores serem de difícil mensuração e as suas determinações laboratoriais inviáveis do ponto de vista econômico, os mesmos podem ser indiretamente avaliados levando-se em consideração o manejo ao qual os recém-nascidos serão ou foram submetidos, tais como as condições de higiene aonde permanecerão nos primeiros dias de vida (se contaminado ou não) e se os colostros ingeridos por esses neonatos são oriundos de vacas nativas, os quais possivelmente proverão melhor qualidade imunizadora.

A ausência de anticorpos específicos pode ser, a nosso ver, o principal fator para explicar a morte de alguns bezerros neonatos, possuidores de concentrações adequadas de imunoglobulinas séricas. Em contrapartida, existem casos de bezerros com comprovada falha de transferência de imunidade passiva que permanecem saudáveis, mesmo a concentração total de imunoglobulinas encontrando-se em níveis inadequados, muito provavelmente pela pequena exposição aos patógenos e/ou devido à existência de anticorpos específicos contra os agentes agressores daquele meio (Paré et al. 1993, Rea et al. 1996, Barrington \& Parish 2001).

Sabe-se que a resposta humoral é específica, isto é, anticorpos diferenciados são produzidos a partir de cada estímulo antigênico (Tizard 2002). Desta maneira, quanto mais rico for o desafio antigênico materno, melhor será o colostro. É extremamente importante a correlação entre os antígenos ambientais aos quais os bezerros serão expostos e os anticorpos presentes no colostro, no momen- to da ingestão; ou seja, o ambiente antigênico do neonato deve ser o mais próximo possível ao da sua mãe, no final de gestação (Wittum \& Perino 1995). Deve-se, portanto, dar especial atenção às vacas gestantes, visando melhorar a qualidade do colostro produzido (Kohara et al. 1997, Vaala et al. 2006). Um dos pontos importantes para se atingir tal objetivo, é a remoção das fêmeas, no mínimo, um mês antes do início da produção colostral, para o piquete onde os neonatos permanecerão nos primeiros dias (por volta de dois meses antes da data prevista para o parto), dando tempo para que as mesmas travem contato com os antígenos locais, desenvolvam resposta imune a esses estímulos antigênicos, e transfiram, tal resposta, para o colostro (Barrington \& Parish 2001).

Caso essas condições não sejam obedecidas, bezerros, que embora tenham ingerido quantidade satisfatória de colostro, podem se comportar como animais com falha de transferência de imunidade passiva e apresentarem maior tendência ao desenvolvimento de desordens infecciosas, como diarréias, distúrbios respiratórios ou mesmo septicemias (Feitosa et al. 2001).

Um programa vacinal materno é também indispensável para a boa proteção do recém-nascido, priorizando aquelas vacinas que, indubitavelmente, aumentariam a resistência imune dos bezerros nos primeiros dias de vida, minimizando, assim, a ocorrência de doenças comumente observadas no período neonatal (van Donkersgoed et al. 1995, Kohara et al. 1997, Gerdts et al. 2004, Vaala et al. 2006). Desta forma, a avaliação das concentrações séricas de alguns componentes sanguíneos não pode ser considerada, por si só, como parâmetro decisório e definitivo para estabelecer se um bezerro recém-nascido terá maior ou menor chance de sobrevivência. O estado nutricional do neonato, a existência de anticorpos específicos para os antígenos circulantes na secreção colostral das mães, além do nível de contaminação do ambiente em que esse animal permanecerá nas suas primeiras horas de vida e do grau de virulência do(s) agente(s) agressor(es) presentes no mesmo, devem ser sempre considerados, quando da interpretação dos resultados laboratoriais (Vihan 1988).

Vale salientar a possibilidade de boa parte dos bezerros recém-nascidos tornarem-se doentes antes mesmo de ingerir o colostro (fase pré-colostral), processo que os tornaria imunodeficientes, pois, provavelmente, mamariam menor quantidade de colostro (Vaala et al. 2006, Radostits et al. 2007). Nesse sentido, a avaliação conjunta dos resultados e objetivos deste trabalho e os conhecimentos explicitados na literatura pertinente, permitiram a suposição de que nem sempre a constatação da ausência de concentrações séricas adequadas de imunoglobulinas em bezerros neonatos, implicaria efetivamente na ocorrência de doenças, evoluindo para desenlace fatal; ao contrário, esses resultados inscritos em zonas de alarme devem ser considerados como indicadores de maior probabilidade de morbidade e mortalidade no plantel, endossando a importância de algumas medidas de segurança, tais como o 
fornecimento de colostro de boa qualidade, no momento preciso e em quantidade suficiente para manter a higidez do plantel e favorecer a sobrevivência dos bezerros recém-nascidos, ratificando as recomendações dos trabaIhos de Smith \& Little (1922), McGuire \& Adams (1982), Barrington \& Parish (2001).

Quando os valores individuais para a proteína total, imunoglobulina $\mathrm{G}$, fração gamaglobulina e atividade sérica de gamaglutamiltransferase (Quadros 3 a 6) obtidos de amostras sanguíneas de bezerros holandeses, e/ou mestiços desta raça, bem como os da raça Nelore, com 24 e 48 horas de vida, foram levados em consideração, constatou-se que a taxa de prevalência de falha de transferência de imunidade passiva observada no presente trabalho variou, de maneira geral, de 10-22\%, porcentagens estas bem próximas aos índices de mortalidade de bezerros estimados por Benesi (1996) e Feitosa et al. (2001). O tempo de maior vulnerabilidade parece ser mais elevado em bezerros nelores, já que a produção autógena de imunoglobulinas ocorreria somente a partir dos 60 dias de vida (Amorim 2002), ao contrário dos recém-nascidos da raça Holandesa, cuja concentração mínima de anticorpos no sangue ocorre por volta de 30 dias (Feitosa et al. 2001, Costa 2000), o que torna os animais da raça de corte mais suscetíveis a contrair infecções nesta crítica faixa etária (Costa et al. 2007).

De maneira geral, a falha de transferência de imunidade passiva variou de 10 a $20 \%$ em ambas as raças (Holandesa e Nelore), na dependência do componente sanguíneo e dos valores padrões escolhidos para a sua estimativa e interpretação. Levando-se em consideração somente os valores estabelecidos para a imunoglobulina $\mathrm{G}$, os bezerros da raça Holandesa possuíam maiores taxas de faIha de imunidade passiva do que os bezerros nelores, às 24 e 48 horas de vida.

\section{REFERÊNCIAS}

Amorim R. 2002. Valores séricos e hepáticos de elementos minerais, atividade sérica da ceruloplasmina, hemograma, proteinograma e metabolismo oxidativo dos neutrófilos em bezerros da raça Nelore, nascidos de mães com nutrição adequada ou inadequada em cobre e zinco. Tese de Doutorado, Faculdade de Medicina Veterinária e Zootecnia, Universidade Estadual Paulista, Botucatu. 158p.

Barragry T. 1997. Calf diarrhoea. Irish Vet. J. 50:49-58.

Barrington G.M. \& Parish S.M. 2001. Bovine neonatal immunology. Vet. Clin. North Am., Food Anim. Pract. 17:463-476.

Barrington G.M. \& Parish S.M. 2002. Ruminant immunodeficiency diseases, p.1600-1602. In: Smith B.P. (Ed.), Large Animal Internal Medicine. $3^{\text {rd }}$ ed. Mosby, St Louis.

Benesi F.J. 1996. Diarréia infecciosa neonatal dos bezerros. I Simpósio Pfizer sobre Doenças Infecciosas e Vacinas para Bovinos. Pfizer, São Paulo, p.15-24.

Biswal S.P., Dutta N.K. \& Mishra P.R. 1993. Estimation of total serum protein and immunoglobulin level in neonatal calves. Indian Vet. J. 70:7-9.

Braun J.P., Rico A.G., Benard P., Thouvenot J.P. \& Bonnefis M.J. 1978. Blood and tissue distribution of gamma glutamyl transferase in calves. J. Dairy Sci. 61:596-599.

Cortese V.S. 2009. Neonatal imunnology. Vet. Clin. Food Anim. Pract. 25:221-227.
Costa J.N. 2000. Leucograma, metabolismo oxidativo dos neutrófilos, proteinograma e imunoglobulinas de bovinos da raça Holandesa (Bos taurus): influência da idade e da suplementação com vitamina E (acetato de DL-alfa-tocoferol). Tese de Doutorado, Faculdade de Medicina Veterinária e Zootecnia, Universidade Estadual Paulista, Botucatu. 192p.

Costa M.C., Flaiban K.K.M.C., Coneglian M.M., Feitosa F.L.F., Balarin M.R.S. \& Lisboa J.A.N. 2007. Transferência de imunidade passiva em bezerros das raças Nelore e Limousin e proteinograma sérico nos primeiros quatro meses de vida. Pesq. Vet. Bras. 28:410-416.

Donovan G.A., Badinga L., Collier R.J., Wilcox C.J. \& Braun R.K. 1986. Factors influencing passive transfer in dairy calves. J. Dairy Sci. 69:754-759.

Fagliari J.J., Oliveira E.C., Pegorer M.F., Ferrante Júnior L.C. \& Campos Filho E. 1996. Relação entre o nível sérico de gamaglobulinas e as atividades de gamaglutamiltransferase, fosfatase alcalina e aspartato aminotransferase de bezerros recém-nascidos. Arq. Bras. Med. Vet. Zootec. 48:225-232.

Fahey J.L. \& McKelvey E.M. 1965. Quantitative determination of serum immunoglobulins in antibody agar plates. J. Immunol. 94:84-90.

Feitosa F.L.F. 1998. Dinâmica do proteinograma e da atividade da gamaglutamiltransferase no soro sanguíneo de bezerros desde o nascimento até um ano de vida e de vacas antes e após o parto, da raça Holandesa. Tese de Doutorado, Faculdade de Medicina Veterinária e Zootecnia da Universidade de São Paulo, Universidade de São Paulo, São Paulo. 219p.

Feitosa F.L.F. \& Birgel E.H. 2000. Variação da concentração de imunoglobulinas $\mathrm{G}$ e $\mathrm{M}$, de proteína total e suas frações eletroforéticas e da atividade da gamaglutamiltransferase no soro sanguíneo de vacas holandesas, antes e após o parto. Arq. Bras. Med. Vet. Zootec. 52:111-116.

Feitosa F.L.F., Birgel E.H., Mendes L.C.N \& Perri S.H.V. 1999. Relação entre a concentração de imunoglobulinas colostrais e a transferência de imunidade passiva para bezerros da raça Holandesa após ingestão voluntária de colostro. Ciênc. Vet. Tróp. 2(3):160-168.

Feitosa F.L.F., Birgel E.H., Mirandola R.M.S. \& Perri S.H.V. 2001. Diagnóstico de falha de transferência de imunidade passiva em bezerros através da determinação de proteína total e de suas frações eletroforéticas, imunoglobulinas $\mathrm{G}$ e $\mathrm{M}$ e da atividade da gamaglutamiltransferase no soro sanguíneo. Ciência Rural 31:251255.

Friedman H.S. 1961. A standardized procedure for serum protein electrophoresis on cellulose acetate membrane strips. Clin. Chim. Acta 6:775-781.

Garry F., Adams R. \& Aldrige B. 1993. Role of colostral transfer in neonatal calf management: Current concepts in diagnosis. Compend. Contin. Educ. Pract. Vet. 15:1167-1175.

Gerdts V., Tsang C., Griebel P.J. \& Babiuk L.A. 2004. DNA vaccination in utero: A new approach to induce protective immunity in the newborn. Vaccine, 22:1717-1727.

Gornall A.G., Bardawill C.J. \& David M.M. 1949. Determination of serum protein by means of biuret reaction. J. Biol. Chem. 177:751-766.

Guy M.A., McFadden T.B., Cockrell D.C. \& Besser T.E. 1994. Regulation of colostrum formation in beef and dairy cows. J. Dairy Sci. 77:3002-3007.

Halliwell R.E.W. \& Gorman N.T. 1989. Veterinary Clinical Immunology. W.B. Saunders, Philadelphia. 548p.

Heath S.E. 1992. Neonatal diarrhea in calves: Investigation of herd management practices. Compend. Contin. Educ. Pract. Vet. 14: 385-395.

Kohara J., Hirai T., Mori K., Ishizaki H. \& Tsunemitsu H. 1997. Enhancement of passive immunity with maternal vaccine against newborn calf diarrhea. J. Vet. Med. Sci. 59:1023-1025.

Kremers B., Briere R.O. \& Batasakis J.G. 1967. Reflectance 
densitometry of cellulose acetate protein electrophoresis. Am. J. Med. Technol. 33:28-34. (Apud Strufaldi B. 1987)

Mancini G., Carbonara A.O. \& Heremans J.F. 1965. Immunochemical quantitation of antigens by single radial immunodifusion. Immunochem. 2:235-244.

McGuire T.C. \& Adams D.S. 1982. Failure of colostral immunoglobulin transfer to calves: Prevalence and diagnosis. Compend. Contin. Educ. Pract. Vet. 4:35-40.

Naylor J.M., Kronfeld D.S., Bech-Nielsen S. \& Bartholomew R.C. 1977. Plasma total protein measurement for prediction of disease and mortality in calves. J. Am. Vet. Med. Assoc. 171:635-638.

Norheim K. \& Simensen E. 1985. An epidemiological study of factors affecting serum IgG levels in dairy calves. Nord. Vet. Med. 37:121-135.

Paré J., Thurmond M.C., Gardners A. \& Picanso J.P. 1993. Effect of birthweight, total protein, serum IgG and Packed Cell volume on risk of neonatal diarrhea in calves on two California daires. Can. J. Vet. Res. 57:241-246.

Paris T.N.N., Quedraogo G., Rico A.G., Bezzile P. \& Braun J.P. 1992. Interêt de la gamma- glutamyl transférase sérique et de la protidêmie totale pour le controle de la prise colostrale chez les veaux nouveaunés. Rec. Méd. Vét. 168:43-47.

Pearson E.G. \& Craig A.M. 1980. The diagnosis of liver disease in equine and food animals. Mod. Vet. Pract. 61:233-237.

Perino L.J., Sutherland R.L. \& Woollen N.E. 1993. Serum gammaglutamyltransferase activity and protein concentration at birth and after suckling in calves with adequate and inadequate passive transfer immunoglobulin G. Am. J. Vet. Res. 54:56-59.

Perino L.J., Wittum T.E. \& Ross G.S. 1995. Effects of various risk factors on plasma protein and serum immunoglobulins concentrations of calves at postpartum hours 10 and 24. Am. J. Vet. Res. 56:1144-1148.

Pugh D.G. 2002. Sheep and Goat Medicine. W.B. Saunders, Philadelphia. 468p.

Radostits O.M., Gay C.C., Hinchcliff K.W. \& Constable P.E. 2007. Veterinary Medicine. $10^{\text {th }}$ ed. W.B. Saunders, London. 2156p.
Rea D.E., Tyler J.W., Hancock D.D., Besser T.E., Wilson L., Krytenberg D.S. \& Sanders S.G. 1996. Prediction of calf mortality by use of tests for passive transfer of colostral immunoglobulin. J. Am. Vet. Med. Assoc. 208:2047-2049.

Selim S.A., Smith B.P. \& Cullor J.S. 1995. Serum immunoglobulins in calves: Their effects and two easy reliable means of measurement. Vet. Med. 90:387-404.

Smith B.P. 2002. Large Animal Internal Medicine. $3^{\text {rd }}$ ed. Mosby, St Louis. $1735 p$.

Smith T. \& Little R.B. 1922. The significance of colostrum to the newborn calf. J. Exp. Med. 36:181-198.

Soares Filho P.M., Bélem P.A.D., Ribeiro Júnior J.I. \& Salcedo J.H.P. 2001. Concentrações de imunoglobulinas $G$ em colostro de vacas mestiças Holandês-Zebu. Ciência Rural 31:1033-1037.

Strufaldi B. 1987. Prática de Bioquímica Clínica. Faculdade de Ciências Farmacêuticas, USP, São Paulo. 399p.

Szasz G. 1969. A kinetic photometric method for serum gamma glutamyl transpeptidase. Clin. Chem. 15:124-136.

Tizard I.R. 2002. Imunidade do feto e do recém-nascido, p.233-246. In: Tizard I.R. (Ed.), Imunologia Veterinária: uma introdução. $6^{a}$ ed. Roca, São Paulo.

Vaala W.E., House J.K. \& Madigan J.E. 2006. Conduta inicial e exame físico do neonato, p.277-293. In: Smith B.P. Medicina Interna de Grandes Animais. $3^{\text {a }}$ ed. Manole, Barueri.

Van Donkersgoed J., Guenther C., Evans B.N., Potter A.A. \& Harland R.J. 1995. Effects of various vaccination protocols on passive and active immunity to Pasteurella haemolytica and Haemophilus somnus in beef calves. Can. Vet. J. 36:424-429.

Vihan V.S. 1988. Immunoglobulin levels and their effect on neonatal survival in sheep and goats. Small Rumin. Res. 1:135-144.

Wittum T.E. \& Perino L.J. 1995. Passive immune status at postpartum hour 24 and long-term health and performance of calves. Am. J. Vet. Res. 56:1149-1154.

Zar J.H. 1999. Biostatistical Analysis. $4^{\text {th }}$ ed. Prentice-Hall, New Jersey. 930p. 